\title{
Papillary Conjunctivitis
}

National Cancer Institute

\section{Source}

National Cancer Institute. Papillary Conjunctivitis. NCI Thesaurus. Code C35616.

Conjunctivitis that is characterized by the formation of papillae on the palpebral conjunctiva. 